\title{
Clinical relevance of autonomic nervous system disturbances in pulmonary arterial hypertension
}

\section{To the Editors:}

We read with great interest the editorial by NAEIJE and VAN DE BORNE [1] on clinical relevance of autonomic nervous system disturbances in pulmonary arterial hypertension. This editorial applies to the study of WENSEL et al. [2] investigating heart rate variability and baroreflex sensitivity in patients with severe pulmonary arterial hypertension (PAH).

In their editorial, R. Naeije and P. van de Borne discuss the cause of exercise hyperventilation in $\mathrm{PAH}$, as well as in patients with congestive heart failure, and attribute it mainly to an increased chemosensitivity on the basis of some previous inert gases studies. In fact, three factors determine the ventilatory response to exercise, 1) the $\mathrm{CO}_{2}$ production, 2) the ratio of physiological dead space $(V \mathrm{D})$ to tidal volume $(V \mathrm{~T})$, $V \mathrm{D} / V \mathrm{~T}, 3)$ the arterial $\mathrm{CO}_{2}$ tension or set point. By analysing each factor in quantitative terms, it is possible to determine the role of each in the high ventilatory response observed in patients during exercise without the help of a costly technique.

Computing $V \mathrm{D} / V \mathrm{~T}$ needs to measure arterial carbon dioxide tension $\left(\mathrm{Pa}_{\mathrm{a}}, \mathrm{CO}_{2}\right)$. Using end tidal carbon dioxide tension $\left(P \mathrm{ET}, \mathrm{CO}_{2}\right)$ as a substitute to $\mathrm{Pa}, \mathrm{CO}_{2}$ may be misleading in patients. Indeed, whereas $P$ ET, $\mathrm{CO}_{2}$ is a few mmHg higher than $\mathrm{Pa}, \mathrm{CO}_{2}$ at maximum exercise in normal subjects, $\mathrm{Pa}_{\mathrm{a}} \mathrm{CO}_{2}$ becomes higher than $P \mathrm{ET}, \mathrm{CO}_{2}$ in patients with low perfusion in well ventilated areas of the lungs. Increase in both $V \mathrm{D} / V \mathrm{~T}$ and $P(\mathrm{a}-\mathrm{ET}), \mathrm{CO}_{2}$ in proportion to the degree of exercise limitation has been previously shown in patients with chronic heart failure [3]. The ventilatory response relative to $\mathrm{CO}_{2}$ production increases when metabolic $\mathrm{H}^{+}$production stimulates the carotid bodies to prevent lowering of $\mathrm{pH}$, lowering therefore the $\mathrm{Pa}_{\mathrm{a}} \mathrm{CO}_{2}$. In patients with low cardiac output, anaerobic threshold and excess $\mathrm{H}^{+}$production occurs at a lower oxygen uptake $\left(V^{\prime} \mathrm{O}_{2}\right)$ than in normal subjects. Patients with chronic heart failure have at maximal exercise not only higher $V \mathrm{D} / V \mathrm{~T}$ than healthy subject of similar age and sex but also higher carbon dioxide production relative to $V^{\prime} \mathrm{O}_{2}$. On the basis of arterial blood gases and gas exchange measured breath by breath, WASSERMAN et al. [3] attribute the excessive exercise ventilation in heart failure patients not only to an increase in $V \mathrm{D} / V \mathrm{~T}$ but also to regulation of arterial $\mathrm{pH}$ by the decrease in $\mathrm{Pa}, \mathrm{CO}_{2}$. Arterial $\mathrm{pH}$ remains close to 7.4 at maximal exercise in the more limited heart failure patients whereas it remains above 7.3 in normal subjects.

It is likely that mechanisms similar to those observed in patients with chronic heart failure explain excessive ventilation during exercise in PAH. Without the help of arterial blood gases measurement during exercise showing overcompensation of metabolic acidosis, increased chemosensitivity as an explanation to the increased ventilation during exercise remains very speculative.

In the paper of WENSEL et al. [2], baroreflex sensitivity in patients with pulmonary arterial hypertension was inferred from the slope of the relationship between systolic blood pressure and the heart beat interval to follow spontaneous blood pressure variations. In fact, these authors only analysed baroreceptor control of heart rate. This study by no means proves that the activating afferent baroreceptor input to vagal and sympathetic cardiomotor neurones is impaired. Moreover, variations of systolic blood pressure were spontaneous and therefore only small changes were observed and related to changes in heart rate. Heart rate is dominated by the activity of the cardioinhibitory parasympathetic nervous system and in humans there is tonic level of parasympathetic cardiac nerve firing and little if any sympathetic activity to the heart at rest [4]. Investigating baroreflex needs testing through the full pressure range. Although we agree that this could be dangerous and unrealistic in patients with severe $\mathrm{PAH}$, results with larger variations of pressure exploring the response to both activation and deactivation of baroreceptors by vasopressor drugs or application of neck pressure or suction could have been different. In animals and humans, it has been shown that the decrease in heart rate in response to a vasopressor drug is mediated by vagal efferents since it remains unchanged after cardiac sympathetic blockade. Only the tachycardia induced by nitroglycerine is attenuated by sympathetic blockade and therefore partly related to sympathetic efferents [4]. Moreover dissociation between baroreflex control of microneurographic sympathetic activation and heart rate as previously shown in hypertensive patients cannot be ruled out [5]. From the study of WeNSEL et al. [2], it can only be concluded that PAH is associated with decreased heart rate variability. Further studies are needed to test if it relates to decrease of the vagal tone and carries a prognostic value similar to what has been observed in heart failure and post-myocardial infarction patients.

\section{B. Raffestin and M. Leroy}

Service d'explorations fonctionnelles, Hôpital Ambroise Paré, APHP, UFR Paris Ile de France Ouest, Université de Versailles Saint Quentin, 92104 Boulogne, France.

Correspondence: B. Raffestin, Service d'explorations fonctionnelles, Hôpital Ambroise Paré, 92104 Boulogne, France. E-mail: bernadette.raffestin@apr.aphp.fr

Statement of Interest: A statement of interest for B. Raffestin can be found at www.erj.ersjournals.com/misc/statements.dtl

\section{REFERENCES}

1 Naeije R, van de Borne P. Clinical relevance of autonomic nervous system disturbances in pulmonary arterial hypertension. Eur Respir $J$ 2009; 34: 792-794.

2 Wensel R, Jilek C, Dörr M, et al. Impaired cardiac autonomic control relates to disease severity in pulmonary hypertension. Eur Respir J 2009; 34: 895-901. 
3 Wasserman K, Zhang Y, Gitt A, et al. Lung function and exercise gas exchange in chronic heart failure. Circulation 1998; 97: 2221-2227.

4 Kirchheim HR, Just A, Ehmke H. Physiology and pathophysiology of baroreceptor function and neuro-hormonal abnormalities in heart failure. Basic Res Cardio 1998; 93: Suppl. 1, 1-22.

\section{From the authors:}

Our editorial [1] about the report of WENSEL et al. [2] on autonomic nervous system disturbances in severe pulmonary hypertension discussed possible links between sympathetic activation, chemosensitivity, and hyperventilation in (right) heart failure. According to B. Raffestin and M. Leroy, this is too much speculation. They believe that hyperventilation in (right) heart failure is simply explained by an increased dead space, and that the report by WENSEL et al. [2] is nothing more than a description of heart rate variability.

The figure illustrating our editorial was not meant to support the notion that plots of ventilatory equivalents for carbon dioxide $\left(V^{\prime} \mathrm{E} / V^{\prime} \mathrm{CO}_{2}\right)$ versus end-tidal carbon dioxide tension $\left(P \mathrm{ET}, \mathrm{CO}_{2}\right)$ in pulmonary arterial hypertension $(\mathrm{PAH})$ and in congestive heart failure (CHF) demonstrate an increased chemosensitivity in both conditions. Of course arterial carbon dioxide tension $\left(\mathrm{Pa}_{\mathrm{a}} \mathrm{CO}_{2}\right)$ instead of $\mathrm{PET}, \mathrm{CO}_{2}$ measurements are needed to prove the point, because an increased physiological dead space increases the gradient between arterial and alveolar (end tidal) carbon dioxide tension. Thus, an increase in $V^{\prime} \mathrm{E} /$ $V^{\prime} \mathrm{CO}_{2}$ at a given $P \mathrm{ET}, \mathrm{CO}_{2}$ could theoretically be observed in the presence of a normal $V^{\prime} \mathrm{E} / V^{\prime} \mathrm{CO}_{2}$ to $\mathrm{Pa}_{1} \mathrm{CO}_{2}$ relationship. However, as already discussed by JoHNSON [3] some years ago, this is not the case in CHF. The available data in PAH are more limited, but point into the same direction, as summarised in our editorial [1].

Dead space should not be confused with physiological dead space. Dead space is anatomic, with a ventilation/perfusion $\left(V^{\prime} \mathrm{A} / Q^{\prime}\right)$ equal to the infinite. It is measured as a $V^{\prime} \mathrm{A} / Q^{\prime}>100$ by the multiple inert gas elimination technique. Physiological dead space corresponds to abnormally high $V^{\prime} \mathrm{A} / Q^{\prime},>3.3$, and therefore includes anatomic dead space and alveolar dead space. Inert gas elimination studies have shown that dead space is normal or near normal in pulmonary vascular diseases. The same studies have demonstrated that physiological dead space is increased, implying an increase in inefficient or "wasted" ventilation. However, wasted ventilation cannot be a cause of hypocapnia. Alkalosis at rest and at exercise in $\mathrm{PAH}$ patients is a consequence, not a cause, of hyperventilation.

What is the cause of decreased heart rate variability in severe pulmonary hypertension [1]? Heart rate is indeed predominantly under parasympathetic control in healthy subjects. However, there is strong evidence of increased sympathetic nervous system activity related to an increased heart rate in PAH [4], as well as in CHF [5, 6]. B. Raffestin and M. Leroy point to possible pitfalls of the determination of spontaneous baroreflex function. Alternative techniques rely on the administration of vasoactive substances, which, as they acknowledge, is unsafe in $\mathrm{PAH}$, or the neck chamber technique, although this would only explore carotid baroreflex sensitivity.
5 Grassi G, Cattaneo BM, Seravalle G, et al. Baroreflex control of sympathetic nerve activity in essential and secondary hypertension. Hypertension 1998; 31: 68-72.

DOI: $10.1183 / 09031936.00165509$

We agree that more studies are needed to address the complex relationships between the autonomic nervous system, chemosensitibility and high $V^{\prime} \mathrm{A} / Q^{\prime}$ gas exchange in severe pulmonary hypertension and in heart failure. There is a lack of data on ventilatory responses to hyperoxic hypercapnia (central chemoreflex) and isocapnic hypoxia (peripheral chemoreceptors), correlated to ventilatory responses to exercise with $V^{\prime} \mathrm{E} / V^{\prime} \mathrm{CO}_{2}$ plotted as a function of $P a, C_{2}$. This is clinically relevant, as out of proportion ventilation in (right) heart failure is a major cause of deteriorated functional state and exercise-induced dyspnoea.

Original papers require conclusions supported by data. Editorials are for clarification of concepts and formulation of new hypothesis, allowing for reasonable speculation and a bit of provocation.

We thank B. Raffestin and M. Leroy for this interesting debate, which we hope will help trigger further exciting research in still largely unexplored areas of heart-lung interaction pathophysiology.

\section{R. Naeije and P. van de Borne}

Dept of Cardiology, Erasme University Hospital, Brussels, Belgium.

Correspondence: R. Naeije, Dept of Cardiology and Physiology, Erasme Hospital, Université Libre de Bruxelles, 808 Lennik Road, 1070 Brussels, Belgium. E-mail: rnaeije@ulb.ac.be

Statement of Interest: None declared.

\section{REFERENCES}

1 Naeije R, van de Borne P. Clinical relevance of autonomic nervous system disturbances in pulmonary arterial hypertension. Eur Respir J 2009; 34: 792-794.

2 Wensel R, Jilek C, Dörr M, et al. Impaired cardiac autonomic control relates to disease severity in pulmonary hypertension. Eur Respir J 2009; 34: 895-901.

3 Johnson Jr RL. Gas exchange efficiency in congestive heart failure II. Circulation 2001; 103: 916-918.

4 Velez Roa S, Ciarka A, Najem B, et al. Increased sympathetic nerve activity in primary pulmonary hypertension. Circulation 2004; 110: 1308-1312.

5 Azevedo ER, Newton GE, Floras JS, et al. Reducing cardiac filling pressure lowers norepinephrine spillover in patients with chronic heart failure. Circulation 2000; 101: 2053-2059.

6 Kaye DM, Smirk B, Finch S, et al. Interaction between cardiac sympathetic drive and heart rate in heart failure: modulation by adrenergic receptor genotype. J Am Coll Cardiol 2004; 44: 2008-2015. 